Communication

\title{
The $\mathrm{Au}_{25}(\mathrm{pMBA})_{17}$ Diglyme Cluster
}

\author{
James Armstrong and Chris J. Ackerson*
}

Department of Chemistry, Colorado State University, Fort Collins, CO 80523, USA;

james.armstrong@colostate.edu

* Correspondence: Chris.Ackerson@colostate.edu

check for

updates

Citation: Armstrong, J.; Ackerson,

C.J. The $\mathrm{Au}_{25}(\mathrm{pMBA})_{17}$ Diglyme Cluster. Molecules 2021, 26, 2562. https://doi.org/10.3390/molecules 26092562

Academic Editors: Noelia Barrabés and Joanna Olesiak-Bańska

Received: 9 April 2021

Accepted: 26 April 2021

Published: 28 April 2021

Publisher's Note: MDPI stays neutral with regard to jurisdictional claims in published maps and institutional affiliations.

Copyright: (c) 2021 by the authors. Licensee MDPI, Basel, Switzerland. This article is an open access article distributed under the terms and conditions of the Creative Commons Attribution (CC BY) license (https:/ / creativecommons.org/licenses/by/ $4.0 /)$.

\begin{abstract}
A modification of $\mathrm{Au}_{25}(\mathrm{pMBA})_{18}$ that incorporates one diglyme ligand as a direct synthetic product is reported. Notably the expected statistical production of clusters containing other ligand stoichiometries is not observed. This $\mathrm{Au}_{25}(\mathrm{pMBA})_{17}$ diglyme product is characterized by electrospray ionization mass spectrometry (ESI-MS) and optical spectroscopy. Thiolate for thiolate ligand exchange proceeds on this cluster, whereas thiolate for diglyme ligand exchange does not.
\end{abstract}

Keywords: metal nanoclusters; ligand exchange; surface chemistry

\section{Introduction}

The ligation shell surrounding protected metal clusters determine properties of the cluster including solubility, capacitance, biocompatibility, reactivity toward ligand exchange, and catalytic capability [1-5]. Ligand shells of thiolate protected gold clusters can be modified by ligand exchange reactions. When a mixed ligand shell is produced, the product is inexact, representing a statistical distribution of both ligands, summing to the total number of ligands [6,7]. Mixed ligand shells with such a statistical distribution of two or more ligand types can also be produced when multiple ligand types are used in cluster synthesis [8].

A few approaches can produce monofunctional gold clusters. These are desirable for bio-labelling, to create bioconjugates of exclusively 1:1 cluster:biomolecule stoichiometry $[9,10]$. Production of monofunctional clusters and/or nanoparticles can proceed by either of two approaches. One is to purify monofunctional clusters from a statistical distribution which contains multi-functional clusters [10]. Alternatively, a solid phase approach can produce clusters or nanoparticles that are monofunctional [11]. Both approaches represent a substantial and labor-intensive endeavor compared to a typical one-pot direct synthesis of gold nanoclusters.

Previously, our group reported that the 2-phenylethanethiol (PET) protected nanocluster $\mathrm{Au}_{20}(\mathrm{PET})_{15}$ could be assembled into dimers linked by diglyme. The clusters must be synthesized in diglyme as a solvent to observe this behavior [12]. The $\mathrm{Au}_{20}(\mathrm{PET})_{15}$ (diglyme) $\mathrm{Au}_{20}(\mathrm{PET})_{15}$ dimers are in a dynamic equilibrium with $\mathrm{Au}_{20}(\mathrm{PET})_{15}$ protomers. The finding of glyme linked clusters is interpreted as glyme making direct and dative (weak) bonds to gold. The overall finding was surprising due to the high strength of the Au-S bond compared to the bonding strength of diglyme to gold [13]. The overall interpretation is that when diglyme is present as solvent (in high molar quantities), that it can compete with thiolates for bonding to the surface of gold clusters.

\section{Results and Discussion}

$\mathrm{Au}_{25}(\mathrm{SR})_{18}$ is the benchmark thiolate protected gold nanocluster [14]. It is preferentially produced in gold cluster synthesis due to its high stability against thermal etching [15]. This has made it a widely used molecule to establish aspects of gold nanocluster synthesis, ligand exchange, and applications; many properties that are found initially for $\mathrm{Au}_{25}(\mathrm{SR})_{18}$ are later shown to be common to thiolate protected gold clusters in general $[2,16,17]$. 
In this work, we show a modification of p-mercaptobenzoic acid (pMBA) protected $\mathrm{Au}_{25}(\mathrm{pMBA})_{18}$ with a diglyme ligand, resulting in a cluster formulated as $\mathrm{Au}_{25} \mathrm{PMBA}_{17}$ diglyme. Spectroscopic and mass spectrometric analysis establish the existence of this cluster. Ligand exchange with incoming a thiol ligand was attempted, under the hypothesis that the diglyme ligand would preferentially exchange. Unexpectedly, diglyme does not exchange with a thiol ligand in any exchange condition, whereas other thiolate ligands do exchange.

To synthesize the cluster, a $125 \mathrm{~mL}$ Erlenmeyer flask was charged with $24 \mathrm{~mL}$ of $100 \mathrm{mM}$ pMBA in $0.3 \mathrm{M} \mathrm{NaOH}$ in water and a stir bar. Addition of $8 \mathrm{~mL} 100 \mathrm{mM} \mathrm{HAuCl}_{4}$ in diglyme was added dropwise. This creates a clear, yellow solution which is stirred for $30 \mathrm{~min}$ before $0.500 \mathrm{~mL}$ of $10 \mathrm{mM}$ sodium borohydride in diglyme is slowly drip added to the solution over $1 \mathrm{~min}$, resulting in a color change to a deep red color. This solution is collected and diluted from $8 \mathrm{~mL}$ aliquots to $50 \mathrm{~mL}$ with diglyme, $1 \mathrm{~mL}$ of ammonium acetate is added. The product is collected by centrifugation. This results in an aqueous biphasic system, with the reaction products concentrated in the bottom phase at approximately $2 \mathrm{~mL}$ volume and black in color. The black, aqueous phase is then separated using polyacrylamide gel electrophoresis (PAGE.) This typically reveals three products (bands) (Supplemental Figure S1), with the bottom band appearing as a deep red color. All products are thought to be nanocluster sized, however this manuscript focuses on the bottom (red) product because it could be characterized by ESI-MS, whereas the other products could not be characterized by ESI-MS, presumably due to harsh ionization conditions.

The red product is collected by excising the band from of the PAGE gel. The excised gel containing the product is powdered with a mortar and pestle and eluted from the gel by an overnight soak in $10 \mathrm{~mL}$ of water. Gravity filtration through a $150 \mathrm{~mm}$ filter separates the soluble product from the insoluble gel. Products appeared to be stable out to at least two weeks under ambient storage conditions, given the timeline of work of these experiments.

The purified product was analyzed by electrospray ionization-mass spectrometry (ESI-MS). Triethylammonium counterions were added because they improve spectra in ESI-MS of gold nanoclusters [18].

ESI-MS of the purified cluster is shown in Figure 1. There are three apparent groups of peaks. The distance between peaks each grouping allows inference of the species charge, allowing a total mass calculation. The three peak groupings correspond to three charge states $(-3,-4$, and -5$)$ of a nanocluster of atomic mass 7655 a.u. This mass corresponds well with a cluster formula of $\mathrm{Au}_{25} \mathrm{pmba}_{17}$ diglyme. That cluster has a mass of 7655 a.u. when eight of the ligands are deprotonated. Figure 1, inset, shows the simulated ESI mass spectrum for $\mathrm{Au}_{25} \mathrm{pmba}_{17}$ diglyme without eight protons, comparing it to the experimental spectrum. The possibility of other combinations of $\mathrm{Au}$ and pMBA were also considered. Notably, we cannot assign this spectrum to the known Aux(SR)y clusters of nearby formulae, including $\mathrm{Au}_{25} \mathrm{pMBA}_{18}$ (mass 7682 a.u.), $\mathrm{Au}_{23} \mathrm{pMBA}_{16}$ (6981 a.u.), or $\mathrm{Au}_{24} \mathrm{pMBA}_{20}$ (7791 a.u.) [18]. Full spectra are available in Supplemental Figure S2, with peak assignments in Supplemental Table S1. Supplemental Table S2 tabulates the expected masses for each of these clusters and their possible protonation states. Some calculated nanocluster assignments are explored further in Supplemental Table S2. Based on the mass spectrum of Figure 1, the product is assigned as $\mathrm{Au}_{25}(\mathrm{pMBA})_{17}$ diglyme. 


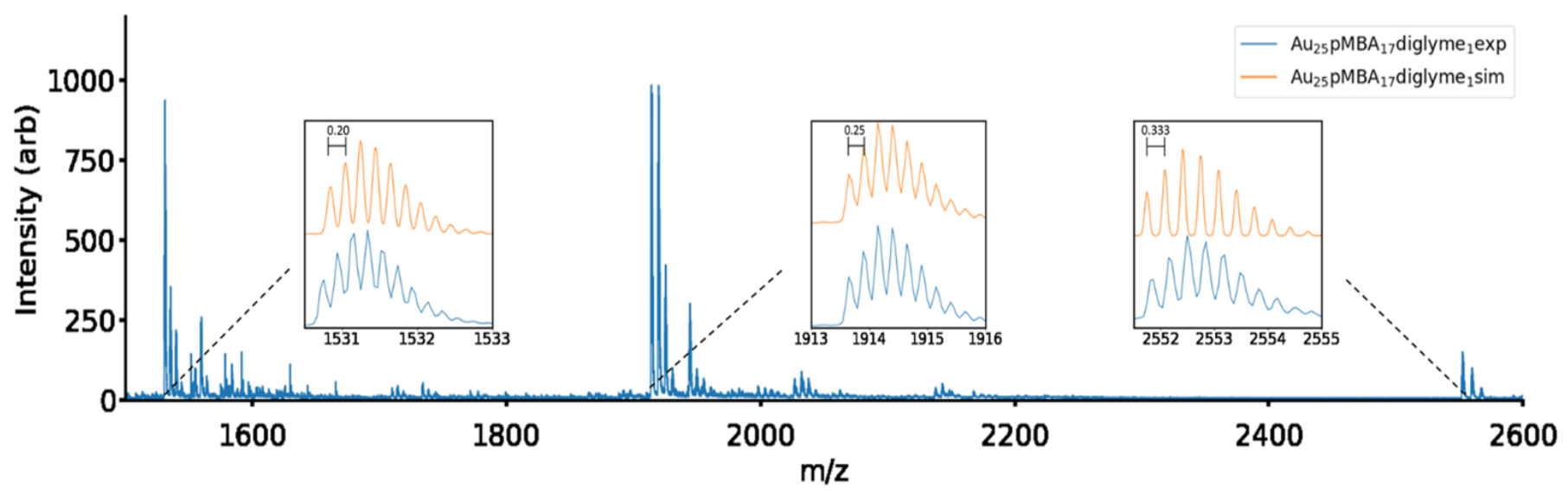

Figure 1. ESI-MS spectra $\mathrm{Au}_{25} \mathrm{pMBA}_{17}$ diglyme, with nine protonated carboxylic acid groups, and eight deprotonated, shows three peak groupings. The peak spacing indicates charge states of $-5,-4$, and -3 , respectively. All three parent peaks can be explained by a $\mathrm{Au}_{25} \mathrm{pMBA}_{17}$ diglyme cluster. Subsequent peaks relate to sodium adducts of the cluster through the carboxylic ligand group.

Supporting this assignment is that the linear absorbance spectrum of $\mathrm{Au}_{25}(\mathrm{pMBA})_{17}$ diglyme is similar, but not identical to the $\mathrm{Au}_{25}(\mathrm{pMBA})_{18}$ spectrum (Figure 2). The $\mathrm{Au}_{25}(\mathrm{pMBA})_{17}$ diglyme spectrum exhibits features at around 410, 440, and $680 \mathrm{~nm}$. These features are similar to the $\mathrm{Au}_{25}(\mathrm{SR})_{18}$ nanocluster, which shows similar features around 430, 470, and $680 \mathrm{~nm}$ [19]. These linear absorption spectral features are attributed to the geometry of $\mathrm{Au}$ in a cluster [20]. This linear absorbance spectrum, therefore, suggests that the cluster consists of 25 gold atoms with 18 ligands in a similar geometric configuration to the very well-studied $\mathrm{Au}_{25}(\mathrm{SR})_{18}$.

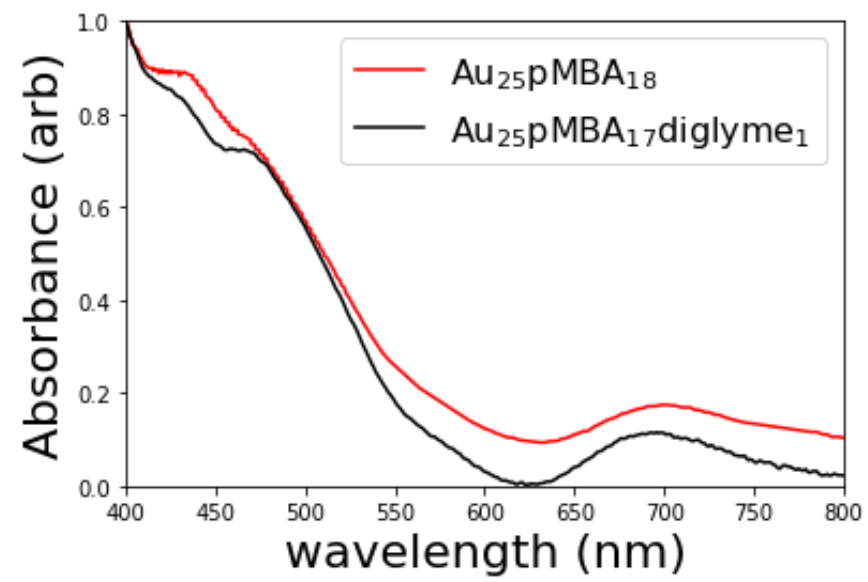

Figure 2. UV-VIS for Au25pMBA 17 diglyme1 (black) is comparable to the UV-VIS spectrum for $\mathrm{Au}_{25} \mathrm{pMBA}_{18}$ (red), reproduced from [19].

We considered that the differences in the linear optical spectrum could be explained as different oxidation states of $\mathrm{Au}_{25}(\mathrm{SR})_{18}$ clusters. $\mathrm{Au}_{25}(\mathrm{SR})_{18}$ clusters are known to be stable and isolable in $+1 / 0 /-1$ oxidation states. This oxidation state is relative to the core gold atoms and is independent of ligand charge. Generally, the oxidation state of a cluster can be determined most reliably by electrochemical means, such as a differential pulse voltammogram to establish the potentials at which the cluster (with a given ligand shell) is in each of the oxidation states. Then a resting potential measurement of a sample can establish the oxidation state of the clusters in the sample. For water-soluble gold clusters, however, electrochemical measurements cannot be made reliably.

Optical spectra of $\mathrm{Au}_{25}(\mathrm{SR})_{18}$ nanoclusters are reported in +1 , neutral, and -1 oxidation states, and show distinguishing features. The linear absorption spectrum for 
$\mathrm{Au}_{24}$ (pMBA) $)_{17}$ diglyme appears most similar to known spectra of +1 oxidation state of $\mathrm{Au}_{25}(\mathrm{SR})_{18}$ at the features around 430 and 470 . However, the $\mathrm{Au}_{24}(\mathrm{pMBA})_{17}$ diglyme spectrum around $680 \mathrm{~nm}$ more closely resembles the -1 oxidation state of $\mathrm{Au}_{25}(\mathrm{SR})_{18}$ [15,21]. Therefore, we cannot conclusively attribute the oxidation state based on the spectrum; The differences in the spectrum between the $\mathrm{Au}_{25}(\mathrm{pMBA})_{18}$ (which can be assigned as oxidation state 0 based on the spectrum) and $\mathrm{Au}_{25}$ (pMBA) ${ }_{17}$ diglyme are likely due to the presence of diglyme in the ligand shell.

The finding of a synthesis that produces a monofunctional $\mathrm{Au}_{25} \mathrm{pMBA}_{17}$ diglyme cluster prompted study of ligand exchange characteristics. Incoming ligand feeds of 3-mercaptopropionic (3-MPA) acid to pMBA were tested from a 1:1 ratio of incoming ligand:cluster, up to 10,000:1 (Supplemental Figures S3 and S4). Solution $\mathrm{pH}$ was varied from 6 to 11; At $\mathrm{pH}$ values below 6 the clusters are insoluble. Temperatures from room temperature to $60^{\circ} \mathrm{C}$ were attempted. In all cases, ESI-MS spectra of the ligand exchange products revealed exchange of pMBA for 3-MPA, but no exchange of diglyme for 3-MPA. Interestingly, synthesis was not viable under similar conditions with other glymes, and exchange of diglyme for new incoming glyme's was not observed.

Figure 3 shows the ESI-MS spectrum of a ligand exchange reaction executed with a 1000-fold excess of 3-MPA for $30 \mathrm{~min}$ at room temperature. This represents a typical result. In Figure 3, each peak can be attributed to the exchange of a pMBA ligand for a 3-MPA ligand, as annotated in the figure. In this reaction condition, we observe the exchange of up to five ligands, with two ligand-exchange appearing as the dominant product. There is no evidence of diglyme exchange.

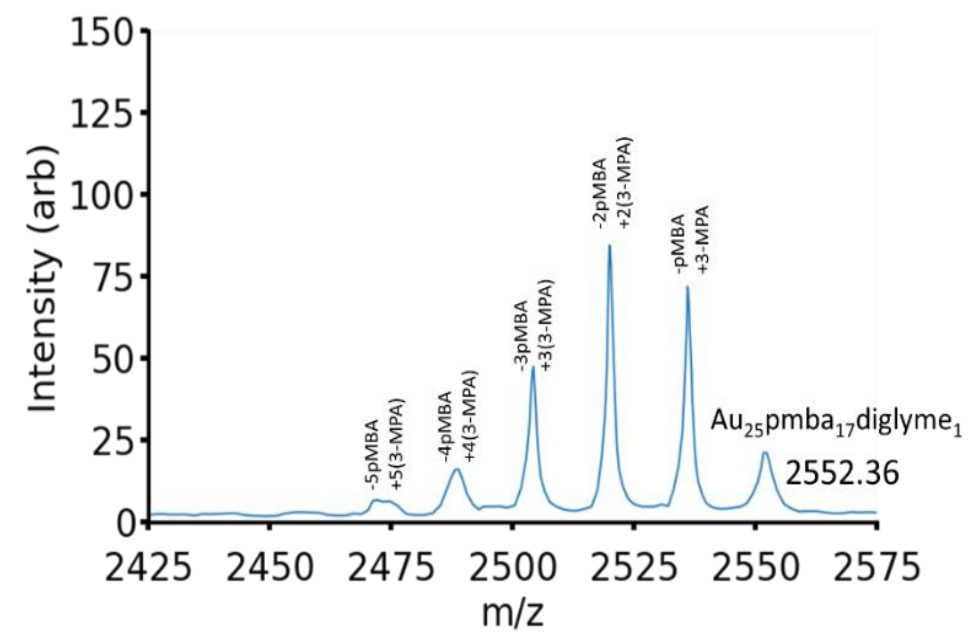

Figure 3. ESI-MS spectra of ligand exchange of Au25 $\mathrm{pMBA}_{17}$ diglyme 1 with 3-mercaptopropionic acid. The furthest right peak can be attributed to the -5 charge state of Au25pMBA 17 diglyme ${ }_{1}$. Each subsequent peak to the left correlates to the exchange of a pMBA ligand for an incoming 3-MPA ligand.

Since the binding energy of thiolate ligands on gold is much more favorable than the binding energy of diglyme on gold, the absence of diglyme for thiol exchange is surprising [12]. We can propose some mechanistic reasons for the absence diglyme exchange. For instance, most ligand exchange on gold clusters proceeds by an associative mechanism which requires solvent exposed gold atoms [2,22]. It may be the case that diglyme ligands are bonded to gold atoms that have no solvent exposure, mechanistically blocking ligand exchange. Diglyme may also be bound in a multidentate manner, whereas the thiolate ligands are monodentate; Multidentate binding of diglyme may interfere mechanistically with ligand exchange.

One ongoing interest is deciphering ligand regiochemistry on gold nanoclusters [17]. Regiochemical control of ligand location on gold nanoclusters is challenging because of the facile nature of inter-particle ligand exchange [7]. The inability of diglyme to exchange with 
thiolate ligands may represent a step toward improved regiochemical control of ligand locations on gold nanoparticles.

Interestingly, this system does not show any evidence for assembly into dimers or larger structures through the diglyme ligand. This was unexpected given our previous observations of $\mathrm{Au}_{20}(\mathrm{PET})_{15}$ dimers linked through a diglyme molecule. The present finding implies an enhanced role of pi-pi stacking between $\mathrm{Au}_{20}(\mathrm{PET})_{15}$ nanoclusters playing a role in assembly, as was initially suggested by IR spectroscopy in our initial report [12]. The carboxylic acid group functional groups on pMBA could prevent this interaction occurring here through steric hindrance or the repulsion of similar surface charges between nanoclusters.

\section{Materials and Methods}

\subsection{Materials}

Gold(III) chloride trihydrate $\left(\mathrm{HAuCl}_{4} \cdot 3 \mathrm{H}_{2} \mathrm{O}\right.$, ACSreagent, $>49.0 \%$ Au basis), sodium borohydride $\left(\mathrm{NaBH}_{4}\right.$, powder, $\left.>98.0 \%\right)$, ammonium acetate $\left(\mathrm{NH}_{4} \mathrm{OAc}\right.$, ACSreagent, $\left.>97.0 \%\right)$, para-mercaptobenzoic acid (pMBA, $>95.0 \%$ ), 3-mercaoptopropionic acid ( $\geq 99 \%$ ), (sodium hydroxide ( $\mathrm{NaOH}$, pellets, certified ACS), 2-Amino-2-(hydroxymethyl)-1,3-propanediol (Tris base, $\geq 99.9 \%)$, boric acid $\left(\mathrm{H}_{3} \mathrm{BO}_{3}, \geq 99.5 \%\right)$, glycerol $\left(\mathrm{C}_{3} \mathrm{H}_{8} \mathrm{O}_{3}, \geq 99.5 \%\right)$, calcium chloride dehydrate $\left(\mathrm{CaCl}_{2} \cdot 2 \mathrm{H}_{2} \mathrm{O}\right.$, crystalline), ethylenediaminetetraacetic acid (EDTA, powder, $>99.4 \%$ ), and diethylene glycol dimethyl ether (diglyme, anhydrous, $99.5 \%$ ) were obtained from Sigma-Aldrich, St. Louis, MO, USA.

\subsection{Synthesis of $A u_{25}(p M B A)_{17}$ diglyme}

First, $8 \mathrm{~mL}$ of $100 \mathrm{mM} \mathrm{HAuCl}_{4} * 3 \mathrm{H}_{2} \mathrm{O}$ in diglyme was added to $24 \mathrm{~mL}$ of $100 \mathrm{mM}$ p-MBA in $0.3 \mathrm{M} \mathrm{NaOH}$ in a $250 \mathrm{~mL}$ Erlenmeyer flask. The reaction mixture was stirred for $30 \mathrm{~min}$ at $0{ }^{\circ} \mathrm{C}$ in an ice bath. The reaction mixture underwent a color change from transparent red to transparent yellow indicating the reduction of gold in the formation of $\mathrm{Au}(\mathrm{I})-[\mathrm{SR}-\mathrm{Au}(\mathrm{I})] \mathrm{x}$ chains. Addition of $10 \mathrm{mM} \mathrm{NaBH}_{4}$ in diglyme, by $100 \mu \mathrm{L}$ aliquots, 1 per minute for $5 \mathrm{~min}$, caused a color change to dark brown/black indicating the formation of nanoclusters. Dilution of $8 \mathrm{~mL}$ aliquots of reaction mixture to $50 \mathrm{~mL}$ was done with diglyme, followed by $1 \mathrm{~mL}$ addition of $5 \mathrm{M}$ ammonium acetate. Centrifugation caused separation into solid black, viscous black layer, and a colorless layer. The viscous layer is separated by TBE-PAGE, giving three products A, B, and C. Polyacrylamide gel electrophoresis (PAGE) is run using a buffer of $89 \mathrm{mM}$ Tris base, $89 \mathrm{mM}$ boric acid, and $2 \mathrm{mM}$ EDTA (TBE). PAGE is run using a VWR power source at a constant voltage of $125 \mathrm{~V}$ for 3:00 h. Samples are mixed $1: 1$ by volume with $50 / 50 \% \mathrm{~b} / \mathrm{v}$ glycerol:water to assist loading into gel.

\subsection{Ligand Exchange of Au25pMBA17diglyme}

An Erlenmeyer flask is charged with $0.1 \mathrm{mM}$ Au25pMBA 17 diglyme. Appropriate volume of 3-mercaptopropionic acid for the intended ratio of incoming ligand:cluster(1:110,000:1) is added and allowed to stir at the appropriate temperature for $30 \mathrm{~min}$. The reaction is quenched by dilution of $8 \mathrm{~mL}$ aliquots of reaction mixture to $50 \mathrm{~mL}$ was done with diglyme, followed by $1 \mathrm{~mL}$ addition of $5 \mathrm{M}$ ammonium acetate. Samples are collected by centrifugation and prepared for ESI-MS analysis.

\subsection{Electrospray Ionization-Mass Spectrometry}

Samples were prepared by dissolving clusters in $1 \mathrm{~mL}$ of $10 \mathrm{mM}$ triethylammonium buffer. These samples were precipitated in $50 \mathrm{~mL}$ ethanol with $1 \mathrm{~mL}$ of $5 \mathrm{M}$ ammonium acetate. Samples were dissolved and precipitated three times in this manner to wash excess diglyme and salts. mass spectrometry-electrospray ionization (ESI-MS) was run using an Agilent Technologies G6220A instrument run in negative ionization mode. Source parameters include: Gas temp $150{ }^{\circ} \mathrm{C}$, vaporizer 120 , gas flow $(\mathrm{L} / \mathrm{min}) 6.0$, nebulizer (psi) 18 , and $\mathrm{V}_{\text {Charge }} 2000$. The scan rate was 1.34. Samples were run at a concentration of $0.01 \mathrm{mg} / \mathrm{mL}$ in water. 


\section{Conclusions}

In conclusion, the highlights of this work include the synthesis of a cluster with a single diglyme ligand that does not participate in subsequent self-assembly. Since these clusters are water-soluble and singly functionalized, they may represent the beginnings of a more straightforward pathway for synthesizing the mono-functional clusters commonly used in bio-labeling [23].

Supplementary Materials: Supplemental Figure S1: TBE-PAGE separation of nanocluster products; Supplemental Figure S2: Full ESI-MS spectra; Supplemental Figures S3 and S4: Ligand exchange with 3-mercaptopropionic acid;-S4, Supplemental Table S1: Peak Assignments from Full Spectra; and Supplemental Table S2: Observed nanocluster mass and potential assignments.

Author Contributions: Conceptualization: J.A., C.J.A.; methodology: J.A.; investigation: J.A.; data curation: J.A.; writing —original draft preparation: J.A.; writing—review and editing: C.J.A. Both authors have read and agreed to the published version of the manuscript.

Funding: This research was funded by the National Science Foundation, grant number 1905179.

Institutional Review Board Statement: Not applicable.

Informed Consent Statement: Not applicable.

Data Availability Statement: Raw data is available from authors upon request.

Acknowledgments: The authors acknowledge W. Scott Compel for helpful discussions.

Conflicts of Interest: The authors declare no conflict of interest.

\section{References}

1. Heinecke, C.L.; Ni, T.W.; Malola, S.; Mäkinen, V.; Wong, O.A.; Häkkinen, H.; Ackerson, C.J. Structural and Theoretical Basis for Ligand Exchange on Thiolate Monolayer Protected Gold Nanoclusters. J. Am. Chem. Soc. 2012, 134, 13316-13322. [CrossRef]

2. Ni, T.W.; Tofanelli, M.A.; Phillips, B.D.; Ackerson, C.J. Structural Basis for Ligand Exchange on $\mathrm{Au}_{25}(\mathrm{SR})_{18}$. Inorg. Chem. 2014, 53, 6500-6502. [CrossRef]

3. Zuber, G.; Weiss, E.; Chiper, M. Biocompatible gold nanoclusters: Synthetic strategies and biomedical prospects. Nanotechnology 2019, 30, 352001. [CrossRef]

4. Luo, Z.; Zheng, K.; Xie, J. Engineering ultrasmall water-soluble gold and silver nanoclusters for biomedical applications. Chem. Commun. 2014, 50, 5143-5155. [CrossRef]

5. Nasaruddin, R.R.; Chen, T.; Yan, N.; Xie, J. Roles of thiolate ligands in the synthesis, properties and catalytic application of gold nanoclusters. Coord. Chem. Rev. 2018, 368, 60-79. [CrossRef]

6. Salassa, G.; Sels, A.; Mancin, F.; Bürgi, T. Dynamic Nature of Thiolate Monolayer in $\mathrm{Au}_{25}(\mathrm{SR})_{18}$ Nanoclusters. ACS Nano 2017, 11, 12609-12614. [CrossRef] [PubMed]

7. Niihori, Y.; Kikuchi, Y.; Kato, A.; Matsuzaki, M.; Negishi, Y. Understanding Ligand-Exchange Reactions on Thiolate-Protected Gold Clusters by Probing Isomer Distributions Using Reversed-Phase High-Performance Liquid Chromatography. ACS Nano 2015, 9, 9347-9356. [CrossRef] [PubMed]

8. Yuan, X.; Zhang, B.; Luo, Z.; Yao, Q.; Leong, D.T.; Yan, N.; Xie, J. Balancing the Rate of Cluster Growth and Etching for Gram-Scale Synthesis of Thiolate-Protected $\mathrm{Au}_{25}$ Nanoclusters with Atomic Precision. Angew. Chem. 2014, 53, 4623-4627. [CrossRef] [PubMed]

9. Wang, H.-H.; Lin, C.-A.J.; Lee, C.-H.; Lin, Y.-C.; Tseng, Y.-M.; Hsieh, C.-L.; Chen, C.-H.; Tsai, C.-H.; Hsieh, C.-T.; Shen, J.-L.; et al. Fluorescent Gold Nanoclusters as a Biocompatible Marker for In Vitro and In Vivo Tracking of Endothelial Cells. ACS Nano 2011, 5, 4337-4344. [CrossRef]

10. Safer, D.; Hainfeld, J.; Wall, J.; Reardon, J. Biospecific labeling with undecagold: Visualization of the biotin-binding site on avidin. Science 1982, 218, 290-291. [CrossRef] [PubMed]

11. Worden, J.G.; Dai, Q.; Shaffer, A.W.; Huo, Q. Monofunctional Group-Modified Gold Nanoparticles from Solid Phase Synthesis Approach: Solid Support and Experimental Condition Effect. Chem. Mater. 2004, 16, 3746-3755. [CrossRef]

12. Compel, W.S.; Wong, O.A.; Chen, X.; Yi, C.; Geiss, R.; Häkkinen, H.; Knappenberger, K.L.; Ackerson, C.J. Dynamic DiglymeMediated Self-Assembly of Gold Nanoclusters. ACS Nano 2015, 9, 11690-11698. [CrossRef]

13. Xue, Y.; Li, X.; Li, H.; Zhang, W. Quantifying thiol-gold interactions towards the efficient strength control. Nat. Commun. 2014, 5, 1-9. [CrossRef]

14. Kang, X.; Chong, H.; Zhu, M. Au ${ }_{25}(\mathrm{SR})_{18}$ : The captain of the great nanocluster ship. Nanoscale 2018, 10, 10758-10834. [CrossRef] [PubMed] 
15. Tofanelli, M.A.; Ackerson, C.J. Superatom Electron Configuration Predicts Thermal Stability of Au 25 (SR) 18 Nanoclusters. J. Am. Chem. Soc. 2012, 134, 16937-16940. [CrossRef] [PubMed]

16. Tracy, J.B.; Crowe, M.C.; Parker, J.F.; Hampe, O.; Fields-Zinna, C.A.; Dass, A.; Murray, R.W. Electrospray Ionization Mass

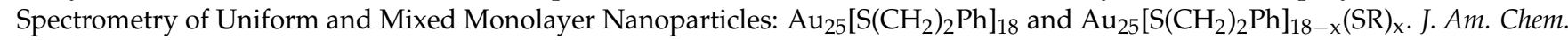
Soc. 2007, 129, 16209-16215. [CrossRef]

17. Hosier, C.A.; Ackerson, C.J. Regiochemistry of Thiolate for Selenolate Ligand Exchange on Gold Clusters. J. Am. Chem. Soc. 2019, 141, 309-314. [CrossRef] [PubMed]

18. Das, A.; Li, T.; Li, G.; Nobusada, K.; Zeng, C.; Rosi, N.L.; Jin, R. Crystal structure and electronic properties of a thiolate-protected $\mathrm{Au}_{24}$ nanocluster. Nanoscale 2014, 6, 6458-6462. [CrossRef] [PubMed]

19. Bertorelle, F.; Russier-Antoine, I.; Comby-Zerbino, C.; Chirot, F.; Dugourd, P.; Brevet, P.-F.; Antoine, R. Isomeric Effect of Mercaptobenzoic Acids on the Synthesis, Stability, and Optical Properties of $\mathrm{Au}_{25}(\mathrm{MBA})_{18}$ Nanoclusters. ACS Omega 2018, 3 , 15635-15642. [CrossRef]

20. Aikens, C.M. Electronic and Geometric Structure, Optical Properties, and Excited State Behavior in Atomically Precise ThiolateStabilized Noble Metal Nanoclusters. Acc. Chem. Res. 2018, 51, 3065-3073. [CrossRef]

21. Qian, H.; Zhu, M.; Wu, Z.; Jin, R. Quantum Sized Gold Nanoclusters with Atomic Precision. Acc. Chem. Res. 2012, 45, 1470-1479. [CrossRef] [PubMed]

22. Guo, R.; Song, Y.; Wang, G.; Murray, R.W. Does Core Size Matter in the Kinetics of Ligand Exchanges of Monolayer-Protected Au Clusters? J. Am. Chem. Soc. 2005, 127, 2752-2757. [CrossRef] [PubMed]

23. Ackerson, C.J.; Powell, R.D.; Hainfeld, J.F. Site-Specific Biomolecule Labeling with Gold Clusters. In Methods in Enzymology; Elsevier: Amsterdam, The Netherlands, 2010; Volume 481, pp. 195-230. 